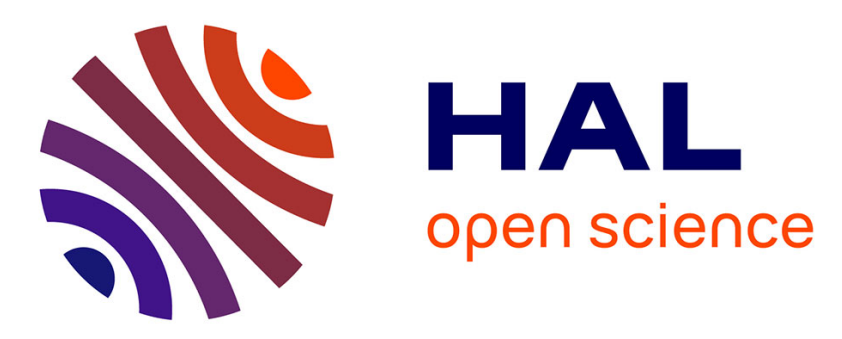

\title{
Natural Cognitive Foundations of Teacher Knowledge
}

Philippe Dessus, Franck Tanguy, André Tricot

\section{To cite this version:}

Philippe Dessus, Franck Tanguy, André Tricot. Natural Cognitive Foundations of Teacher Knowledge: An Evolutionary and Cognitive Load Account. Michel Grangeat. Understanding Science Teacher Professional Knowledge Growth, Sense Publishers, pp.187-202, 2015, 9789463003117. 10.1007/97894-6300-313-1_11. hal-01225902

\section{HAL Id: hal-01225902 \\ https://hal.univ-grenoble-alpes.fr/hal-01225902}

Submitted on 7 Nov 2015

HAL is a multi-disciplinary open access archive for the deposit and dissemination of scientific research documents, whether they are published or not. The documents may come from teaching and research institutions in France or abroad, or from public or private research centers.
L'archive ouverte pluridisciplinaire HAL, est destinée au dépôt et à la diffusion de documents scientifiques de niveau recherche, publiés ou non, émanant des établissements d'enseignement et de recherche français ou étrangers, des laboratoires publics ou privés. 


\title{
PHILIPPE DESSUS, FRANCK TANGUY \& ANDRÉ TRICOT
}

\section{NATURAL COGNITIVE FOUNDATIONS OF TEACHER KNOWLEDGE}

\author{
An Evolutionary and Cognitive Load Account
}

Instructional process management (encompassing instructional design and classroom management) is known to be very complex, mainly due to its context and the large and diverse amount of knowledge driving it: content knowledge, pedagogical knowledge (PK), curriculum knowledge, knowledge of learners and their characteristics, knowledge of educational contexts, pedagogical content knowledge, and knowledge of educational ends (Shulman, 1987). This complexity makes researchers unable to detect well-defined practices, and a knowledge base leading to efficient teaching with low training cost is missing (Koedinger, Booth, \& Klahr, 2013).

The attempts so far to investigate these pieces of knowledge can be categorised in two paths. The first path considers novice vs. expert knowledge comparisons to model knowledge growth across experience (Hogan, Rabinowitz, \& Craven, 2003). The second path considers knowledge bases every teacher needs in order to work efficiently. These two paths both have some concerns. Teachers' expertise is not so clear-cut and the way teachers develop it through experience is difficult to model and diagnose. Further, specifying a comprehensive knowledge base about teaching is often externally-driven (Hattie, 2009; Wang, Haertel, \& Walberg, 1993), listing a superficial knowledge base of 'what works', often unrelated to teachers' beliefs and knowledge and/or their cognitive abilities.

Pedagogical Content Knowledge (PCK), as Shulman (1987, p. 8) argued, is "that special amalgam of content and pedagogy that is uniquely the province of teachers, their own special form of special understanding". This proposition, as well as Shulman's professional knowledge development model, has become widespread in the educational sciences research field. However, some problems can be raised, notwithstanding its vagueness ("special amalgam", also see Kind, 2015). First, teaching is mainly seen as a "learned profession" (see Shulman, 1987, p. 9), while the social and informal facet of this activity, relying on mainly innate abilities, remains unaddressed. Second, we refer to van Driel et al.'s (2001) definition of PCK: "the knowledge the teachers must have in order to teach science" (emphasis added) to highlight that the orientation of such a knowledge base is highly prescriptive in nature: it states appropriate knowledge so that anyone having it can be a good teacher, and many research lines have been oriented to differentiating novices from experts with regard to PCK. Third, this model emphasises a unidirectional way in which teachers' beliefs and knowledge 
influence his or her social behaviour, whereas bidirectional ways are more likely to occur (Rimm-Kaufman \& Hamre, 2010).

The aim of this paper is to explore a cognitive way to define teachers' professional knowledge (TPK), arguing that some 'natural' knowledge, stemming from several human social abilities - and, for many of them, animal - is thus engaged in teaching as well. The actions grounded on such knowledge are undertaken automatically or at a low cognitive load due to the nature of the latter. Some theoretical views on teaching include such an assumption (Csibra, 2007; Csibra \& Gergely, 2011; Strauss, 2005; Strauss \& Ziv, 2012), but so far, little research has investigated teachers' cognitive processes in relation to both natural cognition and Cognitive Load Theory (CLT) (see however Feldon, 2007; Moos \& Pitton, 2013).

The remainder of this paper seeks firstly to consider teachers' actions through the lens of natural cognition and pedagogy, then to set up a framework for teacher cognition and knowledge, showing that several social abilities and knowledge can be used for teaching purposes, and with a low cognitive load. Then, we describe the abilities for teaching as primary vs. secondary knowledge. Eventually, we use this framework to assess or predict which cognitive load is in relation with teachers' performances according to the CLASS, a renowned classroom observation system.

\section{TEACHER COGNITION AND NATURAL PEDAGOGY}

There is a large bulk of work about teacher cognition (e.g., Clark \& Peterson, 1986; Leinhardt \& Greeno, 1986; Yinger, 1986), traditionally splitting teachers' activity into two phases: the tasks teachers perform before actually working with learners (planning phase), and the tasks in the presence of the latter (interactive phase). Natural pedagogy, from a different perspective, posits that teaching is a more integrated and social activity (Csibra \& Gergely, 2011), likely performed in natural contexts using early-emerged communication capabilities like triadic communication about knowledge referents (like eye-contact, turn-taking reactivity, ostensive object or event pointing) (Gergely, Egyed, \& Király, 2007). The main traits of a definition of teaching as a natural ability are summarised as follows (Caro \& Hauser, 1992; Dessus, Mandin, \& Zampa, 2008; Thornton \& Raihani, 2008):

- Teaching is a cooperative activity in which someone (the teacher) "engages in an activity that benefit another, at some cost, or with no immediate benefits to itself" (Thornton \& Raihani, 2008, p. 1825).

- The conveyed knowledge is teleogically and causally opaque (Csibra \& Gergely, 2011), and thus not directly guessable through mere observation.

- The teacher modifies and arranges his or her behaviour (and the environment) to manage easier learning and communication (Sterelny, 2003).

- There is behavioural coordination and matching between the teacher and learner (Strauss, 2005). 
- Intention-reading is one of the core activities involved in natural teaching and is managed through Theory of Mind (ToM) processes (Baron-Cohen, 1994; Rodriguez, 2012).

Briefly put, teaching involves intensive use of social and communicative skills employed by animals, even non-human, and grounded on natural abilities, thus not learnt formally. The next section introduces Geary's theory, predicting which kind of knowledge is to be more or less formally learnt, depending on its epigenetic acquisition.

\section{PRIMARY AND SECONDARY KNOWLEDGE INVOLVED IN INSTRUCTION}

According to Geary (2007), culture is built from cognitive and motivational systems that underlie naive knowledge: "Cultural innovations (e.g., scientific method) are retained across generations through artifacts (e.g., books) and traditions (e.g. apprenticeships). These advances result in a gap between folk knowledge and the theories and knowledge base of the associated sciences and other disciplines" (id., p. 185). This refers to the so-called naive vs. scientific knowledge distinction. The first type of knowledge evolves slowly whereas the second one develops very quickly, exponentially. Naive, folk or primary knowledge $\left(k_{l}\right)$ is implicitly acquired through adaptation to natural, linguistic, social or physical environmental constraints. Scientific, recent or secondary knowledge $\left(k_{2}\right)$, is explicitly acquired through formal education. Primary knowledge has been present in the human species long enough (for 200,000 years) for the species to have evolved so that each individual can acquire it by simply adapting to the social, linguistic, physical or living environments. Secondary knowledge $\left(k_{2}\right)$ is the result of rapid and successive changes and has to be learned explicitly. From this dichotomy, Geary (2007) proposes that:

- Schools are cultural innovations that emerge in societies where cultural and scientific advances have widened the gap between primary knowledge and skills necessary to live in society.

- Schools organise activities for children so that they can acquire the secondary knowledge and skills that will help them bridge the gap between primary knowledge and the requirements of society.

Secondary knowledge-based skills are compiled from primary knowledge and the adaptability of humans to social settings. The primary knowledge can be learned through adaptive learning for many years, mainly before and for the period of schooling. However, from the age of six, a child continues to gain primary knowledge (about himself and group life, the physical environment or living), while beginning to learn secondary knowledge.

Sweller (2008) built on Geary's theory of knowledge to develop a theory of teaching and learning. Primary knowledge, which can be very complex (e.g. foraging), is acquired without teaching, and works by maturation (impregnationadaptation). Secondary knowledge (from cultural or scientific innovations) requires education, effort and motivation, and its learning works either by random generation and selection (discovery learning), or by guided, direct and explicit 
teaching. Secondary knowledge can formally be quite simple (e.g. chess), although difficult and time-consuming to learn. The $k_{1}$ vs. $k_{2}$ alternative explains why learners can acquire some information easily, unconsciously, and without a strong motivation, whereas other types of information may only be acquired at the price of a significant conscious effort, often requiring external motivation. For any $k_{2}$, we need explicit instruction to foster motivation and support learning, which is not requested while acquiring $k_{l}$ (Geary, 2012). This is the main reason schools were created to transmit and learn secondary and demanding knowledge. Teachers have to deploy strategies in order to foster learning, that is, to give learners tasks involving a sufficiently moderate cognitive load so that learners can allocate their cognitive resources to learning $k_{2}$ (Tanguy, Foulin, \& Tricot, 2012).

Our primary argument elaborates on Geary's (2007) and Sweller's (2008) to transpose the $k_{1}$ vs. $k_{2}$ dichotomy from learning to teaching, and posits that teachers use a large number of instructional strategies (communication, social interaction) for pedagogical purposes (i.e. classroom management), more or less consciously and at a low cognitive load (i.e. $k_{1}$ ), while more $k_{2}$-related skills (i.e. more contentfocused) are triggered consciously and at a higher cognitive load, and continuously evolve with changes in culture and society. All in all, $k_{l}$ may be one of the bases of Pedagogical Knowledge, while $k_{2}$ may be linked to Content Knowledge and Pedagogical Content Knowledge. The next section elaborates the relationships between cognitive load and knowledge acquisition (expertise).

\section{COGNITIVE LOAD AND TEACHERS’ EXPERTISE}

Cognitive load refers to the total amount of mental activity imposed by the complexity of a task at a given point in time (Sweller, 1988). Cognitive load depends on the basic characteristics of the information to learn, as well as the pedagogical strategy. Sweller $(1988,2011)$ describes three types of cognitive load:

- Intrinsic cognitive load relates to the level of difficulty of the information delivered to the learner. The quantity of items to be processed and their interactivity during the production of the learning task is considered to play a role in this difficulty. The intrinsic cognitive load is high when there is a lot of information to process and when their inter-relationships are complex. This cognitive load source can be managed by teachers, but this change is limited and very demanding (from an Instructional Design viewpoint).

- Extraneous cognitive load is the cognitive load that is imposed by the structure of the material used (Sweller, 1994), and by inappropriate educational strategies that may interfere with learning strategies. An adequate design of both material and strategies can lessen this amount of unnecessary cognitive load.

- Germane cognitive load is the minimum amount of cognitive load necessary to process information by the learner in order to learn.

According to Cooper (1998) and Sweller (2011), both intrinsic cognitive load and extraneous cognitive load, associated with the presentation of instructional material, can be manipulated by the designers of learning scenarios. 
- First, when the intrinsic cognitive load engaged in a task is low, the learner has sufficient mental resources (i.e. germane cognitive load) in order to learn, even if the task requires a high extraneous cognitive load.

- Second, when the intrinsic cognitive load engaged in a task is high, indicating both that the quantity of items to be processed is too large, and the extraneous cognitive load is also high, the cognitive load exceeds the total mental resources of the learner so there is no relevant cognitive load (germane cognitive load) for learning.

- Eventually, when the presentation of the instructional material sets the extraneous cognitive load to a low level, learning is facilitated, provided that the learner's mental resources are fully available for the task.

The extrinsic cognitive load - and to a lesser extent the intrinsic cognitive load can be controlled by the teacher in order to give the learner sufficient resources to acquire or build the knowledge involved in the learning task. The identification of the knowledge to be taught is therefore essential. In the following section, we provide some evidence about the use of primary knowledge during teaching.

\section{LINKS BETWEEN COGNITIVE LOAD, EXPERTISE AND PRIMARY AND SECONDARY KNOWLEDGE}

With reference to Sweller's (2008) theory, it is necessary to adapt the learning strategy by controlling the extrinsic and intrinsic cognitive load with regard to the type of knowledge to learn in order to facilitate their building by students. For example, the categorisation of living beings (living vs. non-living) may be affiliated with $k_{1}$ and the phylogenetic classification may be related to $k_{2}$ (Geary, 2007). The first type of knowledge is acquired early, regardless of cultural influences (Descola, 2013; Murphy \& Medin, 1985). The handling of this knowledge by the learner engages a small amount of cognitive resources and learning does not seem sensitive to the conditions of instruction: a small amount of information to be processed (low intrinsic cognitive load) and a relatively simple learning device (low extrinsic cognitive load) (Tanguy, Foulin, \& Tricot, 2013) the learning device being the structure of the material used to teach, how to present the information in teaching activities and strategies for learning. The learning device needed to understand the living vs. non-living categorisation is simple because it relies on the use of a dichotomous key with two choices: to decide whether the entity presented is alive or not. Information is presented in a clear manner which limits the extraneous cognitive load for the individual (Tanguy et al., 2012). Teaching such knowledge requires less control by the teacher of content and minimal pedagogical knowledge since these notions are intuitively grasped by students.

On the other hand, the phylogenetic classification of living beings pertains to $k_{2}$. This classification has recently emerged in science and is a product of the evolution of our culture. Learning such knowledge has a significant cognitive cost, first, due to the amount of information to process for designing the affiliation of living beings, which is large (high intrinsic cognitive load) and, second, because it 
requires a suitable learning device: building a phylogenetic tree (high extrinsic cognitive load) (Tanguy et al., 2012). These high values of cognitive load may interfere with a student's learning. The teacher has to manage these costs and limit the amount of information provided in the task, as well as their interactivity (Sweller, 2010). The teaching of such knowledge requires the teacher to have greater control over the content and more sophisticated Pedagogical Content Knowledge.

In a nutshell, pedagogical knowledge related to the content (PCK) is knowledge that a teacher develops to support students in understanding and learning the content. This knowledge is mostly learned during training, but also during teaching practice, at significant cognitive cost. When teachers face difficult and demanding goals, their cognitive load is high and/or their performance is low, and/or the time to achieve the task is long. To perform such difficult tasks, teachers can either:

- ask for help from other humans, which is not very easy while teaching;

- use their primary knowledge; dual processes theories show that in many domains (e.g., decision-making, reasoning, economy), humans frequently use their $k_{l}$ instead of their secondary (rational) knowledge, even when available; or

- learn, in order to become more expert, by acquiring schemas and automatisms which will decrease the intrinsic cognitive load; acquiring expertise is possible by practising (expertise based on problem-solving, on experience) and by learning academic knowledge (expertise based on training, on $k_{2}$ ).

Since asking for help from another teacher is mostly impossible (at least in most instructional environments), teachers only have two solutions to face difficult and demanding goals and to reduce their cognitive load: to learn (i.e. acquire more expertise) or make use of their primary knowledge. The next sections are dedicated to a natural cognition view of the teacher's knowledge that may ground PK and PCK.

\section{NATURAL MECHANISMS UNDERLYING TEACHING: A FRAMEWORK}

We argue that, even before using secondary knowledge, teachers anchor some of their behaviours and knowledge in $k_{l}$. In a given instructional environment (e.g. a classroom), the teacher (and learners as well) is moving and acting to behave adequately, thus using basic social and communicative abilities. Elaborating from Baron-Cohen's (1994) modules of mind reading, below we list by growing order of complexity and required cognitive load three sets of 'modules' (i.e. cognitive functions) that may be activated during teaching and may serve as $k_{l}$. It is worth noting that the functioning of any module necessitates the lower ones (Dessus et al., 2008).

The first set is about detecting intentionality and comprises two different kinds of detection: person and knowledge detection.

- Face Processing and Gaze Direction Detection (Theory of Mind). These modules detect learners' overall attention to infer who places attention on which piece of information, or participates in the lesson flow. Learners' gaze direction is processed for two different purposes: to analyse which data individual 
learners process (individual attention, dyadic); and to analyse which data is jointly processed (joint attention, triadic).

- Knowledge Gap Detection. This ability enables teachers to become aware of pupils' lack of understanding, thus making them able to propose explanations or lacking pieces of knowledge to pupils.

A second set of abilities, grounded on the previous one, is about alignment. As Rodriguez (2012) pointed out, synchrony (or alignment) is a crucial ability for teachers and learners to share a common viewpoint. Two kinds of alignments are necessary:

- Affective and Motivational Alignment: The teacher and learners affectively aligned can share their emotions about their social engagement in instruction and thus their motivation is fostered.

- Activity-focused Alignment: The teacher and learners can smoothly perform activities, being aligned with each other, intentionally or not (Gergely \& Csibra, 2006).

A third set of abilities is action-oriented towards the environment and is termed "arrangement". This set lies on top of the previous set since arranging an activity cannot be done without being aligned with it. Recent work has proven that this environmental arrangement to foster the acquisition of new skills by young conspecifics is often observed in non-human animals (Leadbeater, Raine, \& Chittka, 2006; Sterelny, 2003; Thornton \& McAuliffe, 2006).

- Environment Arrangement: The teacher and learners set up their proximal environment so that it contains the necessary material for teaching/learning.

- Activity Arrangement: The teacher and learners monitor/control their activity and that of others.

Based on top of the three previous modules, the fourth and latest set of abilities allows the triggering of instructional actions intentionally initiated. These actions are the basis of many more sophisticated instructional activities, although used in many other social situations, and are adapted from Merrill (2013).

- Show: explain and/or show specific material or content.

- Conversation: used when discussing certain content or an activity (open or more restricted discussions with learners).

- Feedback Loops: (engaging learners and the teacher in feedback loops to guide their learning).

This framework can serve as a grammar of actions to describe and model instructional contexts and interactions. It describes teaching abilities as nodal actions by growing order of complexity and cognitive load. All of them can be considered as the grounds of $k_{1}$-they are all involved in social learning. The next section aims to validate this framework. Since the role and effect of each of these modules in instructional interactions are hard to detect separately because of their complexity, we use a classroom observation tool to make a first rough assessment of our framework. 


\section{FRAMEWORK VALIDATION WITH THE CLASS OBSERVATION SYSTEM}

We now have to check how teachers actually behave in classrooms with regard to these modules. Since the observation and measure of cognitive load of teacher behaviour is costly, we decided to base our analysis on a well-known classroom observation system, the Classroom Assessment Scoring System (CLASS) (La Paro, Pianta, \& Stuhlman, 2004; Pianta, La Paro, \& Hamre, 2008), which will serve as a proxy to determine which abilities ground which the teacher's behaviour. This is a theoretically-sound system, validated through the observation of more than 4,000 classrooms across the United States of America. Its reliability (across observers and during a school year) and validity (both construct-related and predictive) have been extensively and repeatedly reported. The CLASS is a way to measure the classroom climate and teacher/student relationships in three main domains, distributed across 10 dimensions, which are in turn distributed across several behavioural markers:

- Emotional Support: Positive and negative climate, Teacher sensitivity, Regard for student perspectives.

- Classroom Organisation: Behaviour management, Productivity, Instructional learning formats.

- Instructional Support: Concept development, Quality of feedback, Language modelling.

Measures of climate quality are processed during at least four instructional sessions (20 min each) through Likert scales. Research showed convergent score patterns across the observed classrooms. We assume that these score levels are related to the cognitive load and the type of knowledge that is entailed in: the higher the score, the lower the level of knowledge (and the cognitive load) involved. Research showed that average scores of K-3 classrooms on emotional support and classroom organisation range from moderate to high level (likely relying mostly on $k_{l}$ ), whereas those on instructional support are low in quality (likely relying mostly on $k_{2}$ ).

In order to validate this hypothesis, the different dimensions of the CLASS, together with their indicators, were analysed in function of the ability level mostly involved (see the previous section) by the first author of this paper, a certified CLASS assessor. Some behavioural markers were removed because of their pupilcentration (Teacher Sensitivity $>$ Student Comfort, Behaviour Management $>$ Student Behaviour, Instructional Learning Formats $>$ Student Interest, with the " $>$ " connecting a given dimension with its behavioural markers), as well as the whole "negative climate" dimension. Tables 1 to 3 below depict the CLASS domains/dimensions/indicators (lines) in relation to the four sets of natural abilities they are likely involved in (columns). The grey slots code the likely presence of an ability solicited in the processed dimension. Each ability has a value so that a mean score can be eventually processed by dimension (e.g. Teacher sensitivity>Awareness scores 9 , which is the mean of $\{10,9,8\}$, the respective values of each of the Detection module abilities). 
Emotional support, as depicted in Table 1, mainly involves low-level modules (Detect and Align). The Positive climate dimension is affected by the Detect and Align modules (Knowledge gap detection is not used in this dimension since no formal knowledge is at hand). The Relationships indicator affects the Activity module because it is related to several and diverse abilities: physical proximity, shared activities, peer assistance, matched affect, social conversation). Moreover, Conversation is triggered with the presence of Positive communication and Respect. The Teacher sensitivity dimension mainly taps into the Detect module (Addressing problems excepted, which needs Feedback to work). Eventually, the Regard for student perspectives dimension also closely involves the Detect module. Three of four indicators tap into very close ranges of modules (Detect, Align and Activity arrangement, Flexibility excepted), Student expression excepted, which uses Detect module and Conversation to elicit learners' expression.

The Classroom organisation domain, as depicted in Table 2, is related to the Detect and Align modules like the previous domain is, with an emphasis on knowledge and a greater involvement of the Arrangement-focused module, like in the Preparation dimension. The Instructional learning formats models show more important use of the Initiate module since pedagogical activities can be composed of actions pertaining to the exposition of content ("show" action).

The third and latest CLASS domain (see

Table 3), Instructional support, is composed of Concept development and Quality of feedback, which are very complex and rich activities and use almost the whole range of abilities. Language modelling involves Conversation-based abilities, as well as Detect and Align abilities.

To what extent is the performance across the CLASS dimensions related to the module abilities? We computed a bilateral correlation between the CLASS dimension scores from a world-wide synthesis of the mean CLASS observation results (USA, Finland, the Netherlands, Portugal, France, Chile, Canada) computed by Cosnefroy et al. (2014) and the mean ability scores expressed by dimensions, as shown above. We found a significant correlation: $r=.70, p<.05$. This reveals a strong relationship between the current mean level of quality of teacher-student interactions in classrooms, and the complexity of natural or social skills likely involved in teaching. The more complex the latter are, the lower the corresponding CLASS dimension score involving them. In other words, it is noteworthy that classrooms in most countries score medium or high for Emotional support and Classroom organisation, and these dimensions tap into relatively low-level modules (see Table 1 and Table 2). Conversely, the Instructional support dimension involves modules at the highest level (see Table 3). 
Table 1 - Emotional Support CLASS Domain: Indicators tapping into the modules of our framework

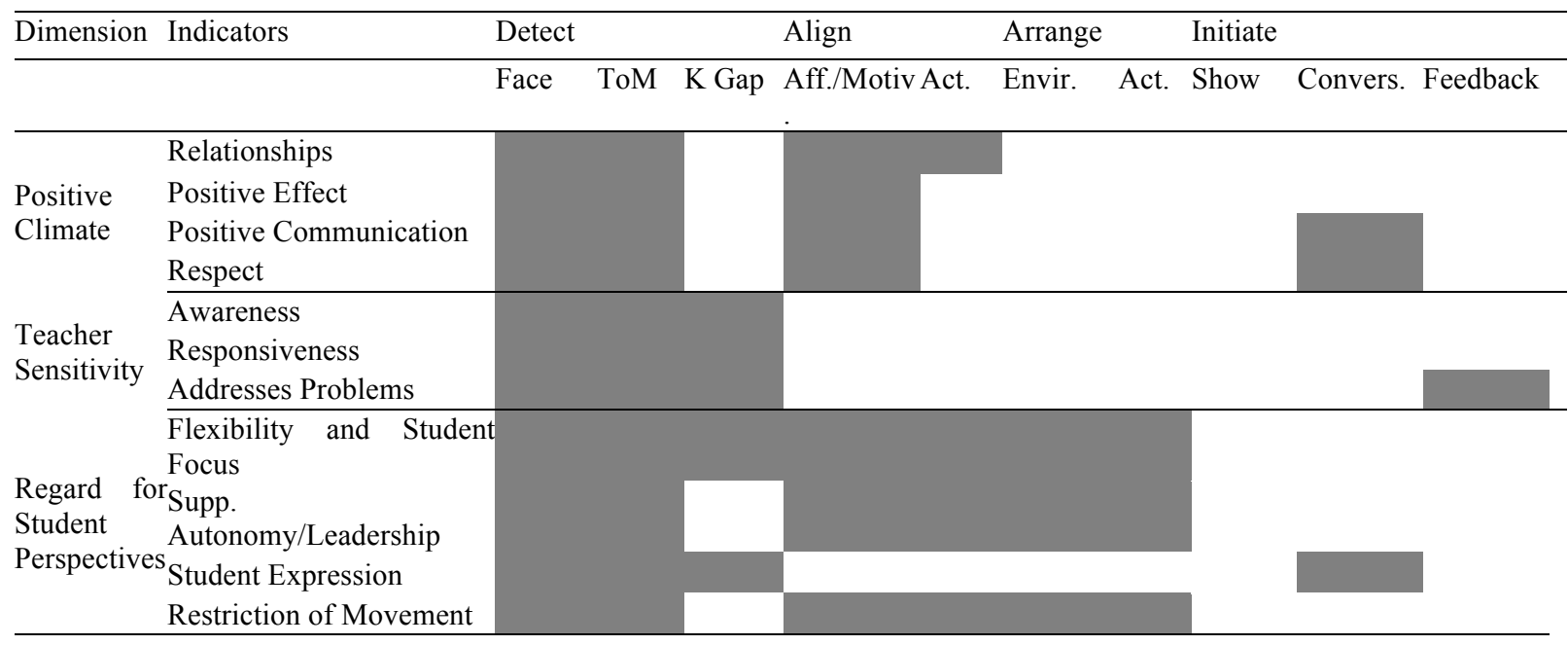


NATURAL FOUNDATIONS OF TEACHER KNOWLEDGE

Table 2 - Classroom Organisation CLASS Domain: Indicators tapping into the modules of our framework

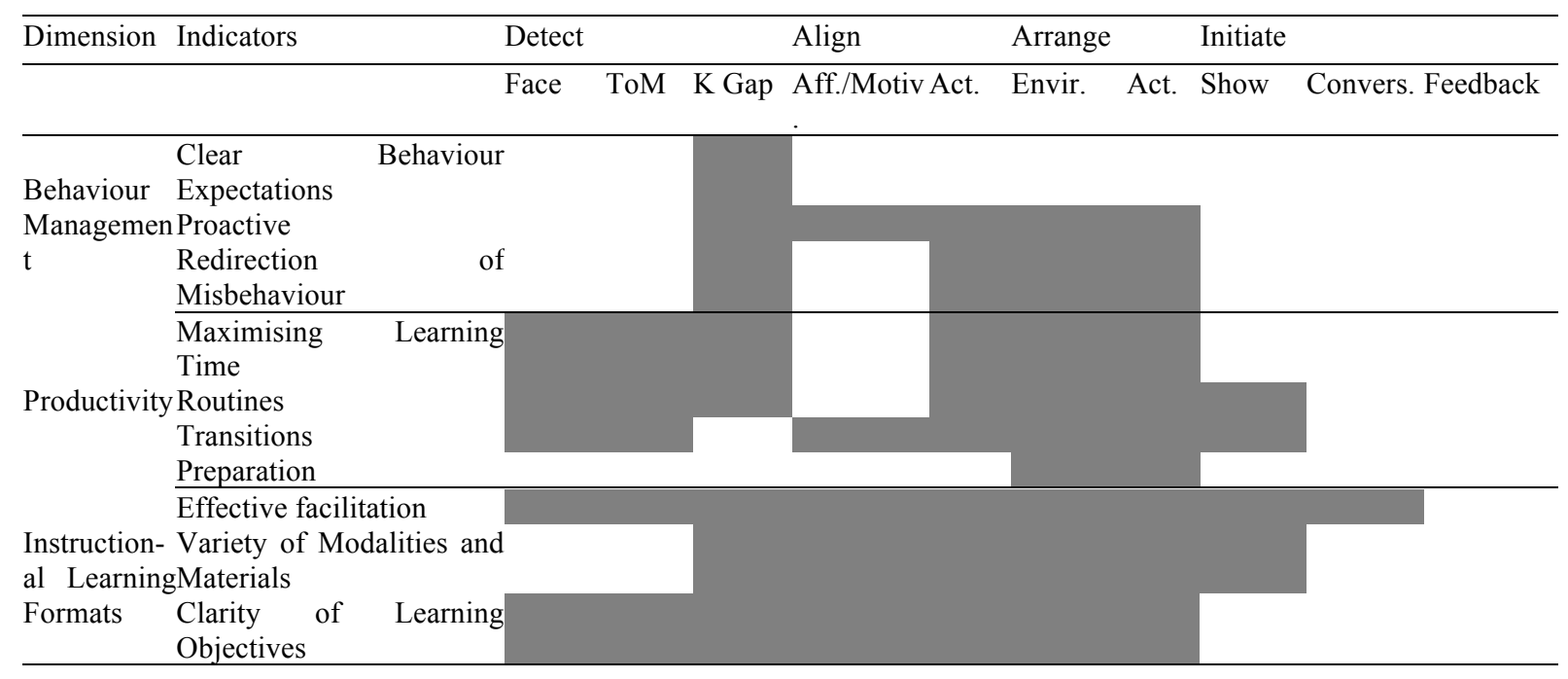


Table 3 - Instructional support CLASS Domain: Indicators tapping into the modules of our framework

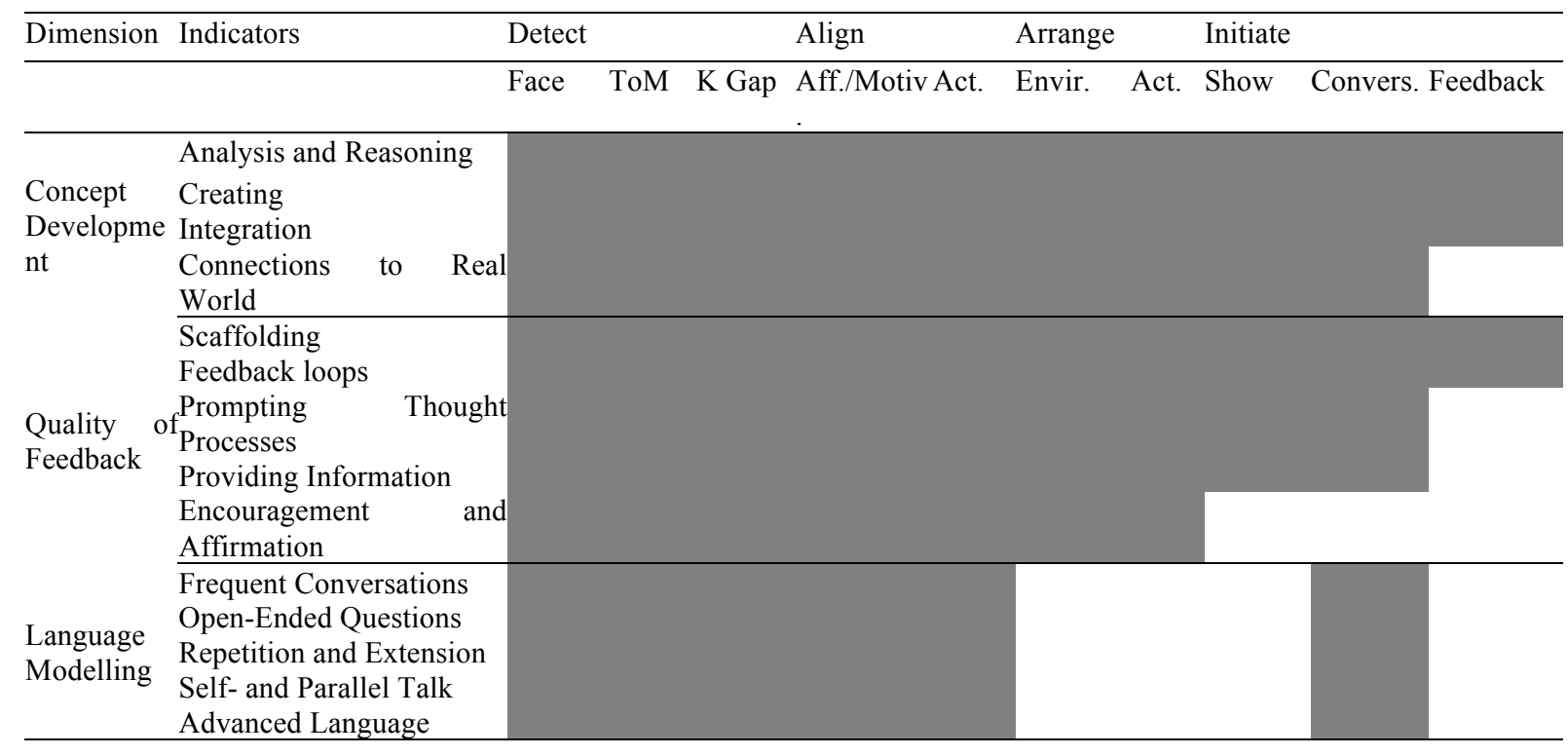




\section{DISCUSSION}

We attempted in this paper to describe what would be the set of primary knowledge involved in teaching, built on top of social skills that can in turn be used in building PCK, a more sophisticated and secondary knowledge-based set of knowledge. We also tried to validate the presence of these skills through the scores obtained from the CLASS, a widespread observation system. We set up a very rough grammar of actions to describe natural teaching processes. These actions were used as a framework to predict the complexity of the teacher-student relationships, as described in the CLASS observation system. This framework is more cognitively plausible than the evermore decomposition of knowledge components. The results showed a strong relationship between the raw description of the abilities involved in each CLASS dimension and the mean score the teachers commonly have in that dimension. This result may explain the fact that knowledge-related processing is more demanding for teachers because it involves higher-level module abilities.

This result is a first step toward a two-tier description of the teacher's knowledge-governing process: primary knowledge, involved in classroom management and social teacher-student interactions, and secondary knowledge for instructional design (planning) and didactical strategies. Historical, evolutionary or comparative approaches should help us understand the different possible weights of these two types of knowledge (e.g., Kline, 2015) and their relationships with human evolved adaptations (Balachandran \& Glass, 2012). But, at this stage of our work, it seems much more prudent to follow dual-process theories and to consider that primary - and secondary - evolved teaching capabilities are always available, and that teachers can switch from one to another. Understanding the mechanisms underlying this switching is a main challenge.

We can list some consequences of the way to study teaching processes. First of all, this framework may be used in a descriptive way, as the basis of a diagnosis on how knowledge is used in teaching: - how $k_{1}$ and $k_{2}$ are actually used in daily classroom practice - how they are related to a measured amount of cognitive load, and - why and when a teacher can switch from the use of one type of knowledge to another. Second, this framework may have a more prescriptive use by separating two kinds of knowledge to be built in teacher development. For example, one way to decrease cognitive load is to consider teaching as a joint activity (see Chapter 4 , Section 1 of this book). Teacher and pupils work together to trigger and maintain joint activities (affect expression, joint attention) aligned with each other (Garrod \& Pickering, 2004; Sahlström, 2001), facilitating their own activity. Another way is to reduce the cognitive load by routinising the first two domains (emotional support and classroom organisation), thereby devoting more cognitive resources to process instructional support-related situations. 


\section{ACKNOWLEDGEMENTS}

We wish to thank David Cross for thoughtful comments, as well as Murray Bales for copy-editing this paper.

\section{REFERENCES}

Balachandran, N., \& Glass, D. J. (2012). PsychTable.org: The taxonomy of human evolved psychological adaptations. Evolution: Education and Outreach, 5(2), 312-320. doi: 10.1007/s12052-012-0428-8

Baron-Cohen, S. (1994). How to build a baby that can read minds: Cognitive mechanisms in mindreading. Cahiers de Psychologie Cognitive/Current Psychology of Cognition, 13(5), 513-552.

Caro, T. M., \& Hauser, M. (1992). Is there teaching in nonhuman animals? The Quarterly Review of Biology, 67, 151-174.

Clark, C. M., \& Peterson, P. L. (1986). Teachers' thought processes. In M. C. Wittrock (Ed.), Handbook of Research on Teaching (3rd ed., pp. 255-296). New York: Mac Millan.

Cooper, G. (1998). Research into cognitive load theory and instructional design. Sydney: UNSW.

Cosnefroy, O., Nurra, C., Joët, G., \& Dessus, P. (2014). "I enjoy reading more and more every day, how come you don't?". Evolution of the interest of first graders in reading over the school year Poster presented to the 3rd Biennial EARLI SIG 5 Conference. Jyväskylä (Finland).

Csibra, G. (2007). Teachers in the wild. Trends in Cognitive Sciences, 11(3), 95-96. doi: 10.1016/j.tics.2006.12.001

Csibra, G., \& Gergely, G. (2011). Natural pedagogy as evolutionary adaptation. Philosophical Transactions of the Royal Society of London B, 366, 1149-1157. doi: 10.1098/rstb.2010.0319

Descola, P. (2013). Beyond nature and culture (J. Lloyd, Trans.). Chicago: University of Chicago Press.

Dessus, P., Mandin, S., \& Zampa, V. (2008). What is teaching? Cognitive-based tutoring principles for the design of a learning environment. In S. Tazi \& $\mathrm{K}$. Zreik (Eds.), Common innovation in elearning, Machine learning and humanoid (ICHSL'6) (pp. 49-55). Paris: IEEE/Europia.

Feldon, D. F. (2007). Cognitive load and classroom teaching: The double-edged sword of automaticity. Educational Psychologist, 42(3), 123-137. doi: 10.1080/00461520701416173

Garrod, S., \& Pickering, M. J. (2004). Why is conversation so easy? Trends in Cognitive Sciences, 8(1), 8-11. doi: 10.1016/j.tics.2003.10.016

Geary, D. C. (2007). Educating the evolved mind: Conceptual foundations for an evolutionary educational psychology. In J. S. Carlson \& J. R. Levin (Eds.), Educating the evolved mind: Conceptual foundations for an evolutionary educational psychology (pp. 1-99). Greenwich, CT: Information Age Publishing.

Geary, D. C. (2012). Application of evolutionary psychology to academic learning. In C. Roberts (Ed.), Applied evolutionary psychology (pp. 78-92). Cambridge, UK: Oxford University Press.

Gergely, G., \& Csibra, G. (2006). Sylvia's recipe: The role of imitation and pedagogy in the transmission of cultural knowledge. In N. J. Enfield \& S. C. Levenson (Eds.), Roots of human sociality: Culture, cognition, and human interaction (pp. 229-255). Oxford: Berg.

Gergely, G., Egyed, K., \& Király, I. (2007). On pedagogy. Developmental Science, 10(1), 139-146. doi: 10.1111/j.1467-7687.2007.00576.x

Hattie, J. (2009). Visible learning. A synthesis of over 800 meta-analyses relating to achievement. New York: Routledge.

Hogan, T., Rabinowitz, M., \& Craven, J. A. (2003). Representation in teaching: Inferences from research of expert and novice teachers. Educational Psychologist, 38(4), 235-247. doi: 10.1207/S15326985EP3804_3

Kind, V. (2015). On the beauty of knowing then not knowing: Pinning down the elusive qualities of PCK. In A. Berry, P. Friedrichsen \& J. Loughran (Eds.), Re-examining Pedagogical Content Knowledge in science education (pp. 178-195). New York: Routledge. 


\section{NATURAL FOUNDATIONS OF TEACHER KNOWLEDGE}

Kline, M. A. (2015). How to learn about teaching: An evolutionary framework for the study of teaching behavior in humans and other animals. Behavioral and Brain Sciences, 38, e31. doi: $10.1017 / \mathrm{S} 0140525 \mathrm{X} 14000090$

Koedinger, K. R., Booth, J. L., \& Klahr, D. (2013). Instructional complexity and the science to constrain it. Science, 342, 935-937. doi: 10.1126/science.1238056

La Paro, K. M., Pianta, R. C., \& Stuhlman, M. (2004). The Classroom Assessment Scoring System: Findings from the prekindergarten year. The Elementary School Journal, 104(5), 409-426.

Leadbeater, E., Raine, N. E., \& Chittka, L. (2006). Social learning: Ants and the meaning of teaching. Current Biology, 16, R323-R325. doi: 10.1016/j.cub.2006.03.078

Leinhardt, G., \& Greeno, J. G. (1986). The cognitive skill of teaching. Journal of Educational Psychology, 78(2), 75-95.

Merrill, M. D. (2013). First principles of instruction. San Francisco: Pfeiffer.

Moos, D. C., \& Pitton, D. (2013). Student teacher challenges: using the cognitive load theory as an explanatory lens. Teaching Education. doi: 10.1080/10476210.2012.754869

Murphy, G. L., \& Medin, D. L. (1985). The role of theories in conceptual coherence. Psychological Review, 92, 289-316.

Pianta, R. C., La Paro, K. M., \& Hamre, B. K. (2008). Classroom assessment scoring system: Manual $K$-3. Baltimore: Brookes.

Rimm-Kaufman, S. E., \& Hamre, B. K. (2010). The role of psychological and developmental science in efforts to improve teacher quality. Teachers College Record, 112(12), 2988-3023.

Rodriguez, V. (2012). The teaching brain and the end of the empty vessel. Mind, Brain, and Education, 6(4), 117-185. doi: 10.1111/j.1751-228X.2012.01155.x

Sahlström, J. F. (2001). The interactional organization of hand raising in classroom interaction. Journal of Classroom Interaction, 37(2), 47-57.

Shulman, L. S. (1987). Knowledge and teaching: Foundations of the new reform. Harvard Educational Review, 57(1), 1-22.

Sterelny, K. (2003). Thought in a hostile world, The evolution of human cognition. Malden: Blackwell.

Strauss, S. (2005). Teaching as a natural cognitive ability: Implications for classroom practice and teacher education. In D. Pillemer \& S. White (Eds.), Developmental psychology and social change (pp. 368-388). New York: Cambridge University Press.

Strauss, S., \& Ziv, M. (2012). Teaching is a natural cognitive ability for humans. Mind, Brain, and Education, 6(4), 186-196. doi: 10.1111/j.1751-228X.2012.01156.x

Sweller, J. (1988). Cognitive load during problem solving. Effects on learning. Cognitive Science, 12, 257-285.

Sweller, J. (1994). Cognitive load theory, learning difficulty, and instructional design. Learning and Instruction, 4(4), 295-312.

Sweller, J. (2008). Instructional implications of David C. Geary's evolutionary educational psychology. Educational Psychologist, 43, 214-216. doi: 10.1080/00461520802392208

Sweller, J. (2010). Element interactivity and intrinsic, extraneous and germane cognitive load. Educational Psychology Review, 22, 123-138. doi: 10.1007/s10648-010-9128-5

Sweller, J. (2011). Cognitive load theory. In J. Mestre \& B. Ross (Eds.), The psychology of learning and motivation: Cognition in education (Vol. 55, pp. 37-76). Oxford: Academic Press.

Tanguy, F., Foulin, J.-N., \& Tricot, A. (2012). Is "primary and secondary knowledge" framework refutable? Paper presented at the 5th Int. Cognitive Load Theory Conference, Tallahassee.

Tanguy, F., Foulin, J.-N., \& Tricot, A. (2013). Effet du guidage sur l'apprentissage de la distinction vivant versus non vivant. Enfance, 2, 159-179.

Thornton, A., \& McAuliffe, K. (2006). Teaching in wild meerkats. Science, 313, 227-229. doi: 10.1126/science. 1128727

Thornton, A., \& Raihani, N. J. (2008). The evolution of teaching. Animal Behaviour, 75, 1823-1836. doi: $10.1016 /$ j.anbehav.2007.12.014 
van Driel, J. H., Veal, W. R., \& Janssen, F. J. J. M. (2001). Pedagogical content knowledge: An integrative component within the knowledge base for teaching. Teaching and Teacher Education, 17, 979-986.

Wang, M. C., Haertel, G. D., \& Walberg, H. J. (1993). Toward a knowledge base for school learning. Review of Educational Research, 63(3), 249-294.

Yinger, R. J. (1986). Examining thought in action : a theoretical and methodological critique of research on interactive teaching. Teaching and Teacher Education, 2(3), 263-282.

\section{AFFILIATIONS}

Philippe Dessus

LSE, Univ. Grenoble Alpes

Grenoble, France

Corresponding author's email address: philippe.dessus@upmf-grenoble.fr

Frank Tanguy

Univ. Bordeaux

Bordeaux, France

André Tricot

UMR 5263 CLLE (CNRS), Univ. Toulouse-2

Toulouse, France 